\title{
Corrosion of steel in concrete due to one and two dimensional chloride ingress
}

\author{
Ze Gyang Zakka ${ }^{1,2, *}$, and Mike Otieno ${ }^{1}$ \\ ${ }^{1}$ School of Civil and Environmental Engineering, University of the Witwatersrand, Johannesburg, South Africa \\ ${ }^{2}$ Department of Building Technology, Abubakar Tafawa Balewa University, Bauchi, Nigeria
}

\begin{abstract}
This paper presents results of an ongoing research of the effect of $1 \mathrm{D}$ and $2 \mathrm{D}$ chloride ingress on concrete resistivity and corrosion rate of steel reinforcement. 12 concrete beams made with concrete of binder blend $\mathrm{PC}(50) / \mathrm{GGBS}(50), \mathrm{w} / \mathrm{b}=0.40,10 \mathrm{~mm}$ steel reinforcement rods at concrete cover of $20 \mathrm{~mm}$ were used in this laboratory based experiment. The steel reinforcement bars were placed at the middle or at an orthogonal corner of the concrete beams subjected to 1D and 2D chloride ingress respectively. A single crack was induced using 3-point bending on one-half of the beams. The beams were exposed to a repeated cycle of 2 weeks ponding in $5 \% \mathrm{NaCl}$ and then air drying in ambient laboratory condition for 2 weeks. The corrosion rate of both cracked and uncracked specimens exposed to $2 \mathrm{D}$ chloride ingress was significantly higher than that of beams exposed to $1 \mathrm{D}$ chloride ingress. The uncracked specimens had lower concrete resistivity values compared to the cracked specimens even though higher corrosion rates were measured.
\end{abstract}

\section{Introduction}

Over the years, corrosion of steel in concrete has been identified as the major cause of concrete deterioration. The steel corrosion is mainly caused by a breakdown (depassivation) of the thin oxide protective layer on the steel surface due to carbonation of the concrete to the depth of the reinforcement bar (carbonation-induced corrosion) or presence of a sufficient concentration of chlorides at the steel surface (chloride-induced corrosion) [1], [2]. Even though chloride-induced corrosion has been reported as the dominant cause of corrosion of steel in concrete, the rising risk of carbonation-induced corrosion due to climate change has also been envisaged [3]. This paper is focused on chloride-induced corrosion.

Chloride-induced corrosion is prevalent in chloride laden environments such as marine zones and areas where chloride based salts (e.g. deicing salts) are utilized. Chlorides can contaminate concrete via use of chloride based admixtures, contamination of mix materials and penetration from the external environment. After steel depassivation, the steel corrosion rate depends on the concrete exposure condition, concrete cover resistance to penetration of corrosion causing agents such as oxygen, moisture and quality of the steel concrete interface [2], [4]-[6].

Apart from initiating the steel corrosion, the presence of chlorides in the concrete influences the ionic composition of the concrete pore solution by making it more conductive; hence, ions tend to flow easily between the anodic and cathodic sites of the corrosion cell. Due to the electrochemical nature of corrosion, its assessment can be conducted indirectly by taking measurements of parameters such as the steel corrosion potential $\left(E_{c o r r}\right)$, concrete resistivity $(\rho)$ and corrosion current density $\left(i_{\text {corr }}\right)$ [7]. The steel corrosion potential measurements, though important, only give an indication of the probability of corrosion of the embedded steel, hence the use of concrete resistivity to predict the risk of steel corrosion has been advocated by various researchers [8]-[12]

Zhang et al. (2016) observed that over the past 40 years most research undertaken on corrosion of steel embedded in concrete have focused on 1D chloride ingress (e.g. in walls and slabs) and though many valuable results have been obtained and successfully applied to service life prediction of field structures, most concrete structures (such as rectangular shaped beam and column elements) are subjected to 2D chloride ingress at their corners [14]. Chloride ion penetration at corners exposed to 2D chloride ingress have been adjudged to be faster due to dimensional interaction of the penetrating chloride from two adjacent faces of the concrete element [14]-[18]. Although some studies have looked at 2D chloride penetration and its influence on corrosion initiation, these researches focused on uncracked concrete [14], [18], [19]. There has also been no report of the effect of 2D chloride penetration on corrosion rate of reinforcement placed at orthogonal corners of concrete elements.

This paper seeks to find the influence of $1 \mathrm{D}$ and $2 \mathrm{D}$ chloride ingress on concrete resistivity and corrosion of steel embedded in PC(50)/GGBS(50).

\footnotetext{
* Corresponding author: 1355200@students.wits.ac.za
} 


\section{Relationship between steel corrosion rate and concrete resistivity}

The relationship between concrete resistivity and corrosion rate can be influenced by a number of factors. In general, most researchers have observed the existence of an inverse linear relationship between corrosion rate and concrete resistivity [9], [20]. Although this is widely accepted, a contrasting relationship has been reported with respect to submerged RC structures, as a decrease in concrete resistivity may not necessarily mean an increase in corrosion rate due to insufficient oxygen at the steel surface to drive the cathodic reaction, thereby causing the corrosion process to slow down. Hence a reduction in concrete resistivity may not in all instances result in an increase in corrosion rate [12].

Temperature influences the kinetics of ion movement; hence an increase in temperature is likely to result in lower concrete resistivity and an increase in corrosion rate, however in concrete with large exposed surface, an increase in temperature may result in the concrete drying out, thereby causing an increase in the concrete resistivity and a subsequent reduction in the corrosion rate [21], [22].

The presence of cracks may also influence the interpretation of concrete resistivity measurements and corrosion rates. The cracks influence chloride transportation mechanism wherein depending on the crack width, they are able to easily penetrate and reach the steel reinforcement [23], [24]. This may result in early corrosion initiation and rapid corrosion propagation; however, the cracks are likely to allow easy drying of the concrete thereby resulting in high values of concrete resistivity and higher corrosion rates. These result trends do not fit into the general assumption that there is an inverse relationship between steel corrosion and concrete resistivity readings.

Corrosion rate estimation in pitting corrosion cases still presents a problem due to localization of the corrosion sites rather than an even spread over the steel reinforcement bar surface [25]. However an exception may apply where the chloride is uniformly spread over reinforcement surface thereby resulting in uniform corrosion.

Apart from the factors already mentioned, concrete resistivity can also be influenced by factors such as; binder composition, age of concrete, concrete pore size and connectivity and relative humidity $(\mathrm{RH})$.

\section{Materials and Methods}

\subsection{Specimen preparation}

A concrete mix $\mathrm{PC}(50) / \operatorname{GGBS}(50)$ with $\mathrm{w} / \mathrm{b}=0.40$, concrete cover to reinforcement of $20 \mathrm{~mm}$ and $10 \mathrm{~mm}$ diameter steel reinforcement bars were used in this laboratory based experiment. 2 sets of concrete beams (total $=12$ number) of size $150 \times 150 \times 625 \mathrm{~mm}$ were cast with reinforcement detail and chloride ingress paths as shown in Figure 1.
One-half of the beams were mechanically cracked using 3 point bending technique while the other half were left uncracked. To aid the formation of a single crack (after the load application) at the beams mid-span, a removable shim was placed in the concrete mold.

The commercial surface of the steel reinforcement bars was retained. The reinforcement bars were also cleaned with acetone before placing them in the concrete (ASTM G1-90: 2003).

The cast beams were cured in water for 28 days, then allowed to air-dry for one week before application of an epoxy sealant on selected surfaces to allow only 1D or 2D chloride ingress (see Figure 1).

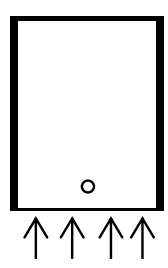

(a) G1Y1N

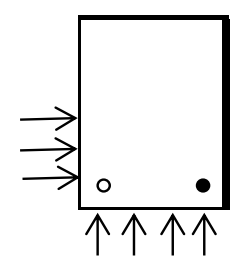

(b) $\mathrm{G} 2 \mathrm{Y} 2 \mathrm{~N}$

\begin{tabular}{|l|l|l|l|l|l|}
\hline$\circ$ & $\begin{array}{l}\text { Uncoated } \mathrm{rft} \\
\text { bar }\end{array}$ & & $\begin{array}{l}\text { Uncoated } \\
\text { conc. Face }\end{array}$ & $\rightarrow$ & $\begin{array}{l}\text { Chloride } \\
\text { ingress path }\end{array}$ \\
\hline$\bullet$ & $\begin{array}{l}\text { Epoxy coated } \\
\text { rft bar }\end{array}$ & - & $\begin{array}{l}\text { Epoxy coated } \\
\text { conc. face }\end{array}$ & \multicolumn{2}{|l}{} \\
\hline
\end{tabular}

$\mathrm{G}$ is concrete made of $\mathrm{PC}(50) / \mathrm{GGBS}(50)$ binder blend G1 is slag concrete exposed to 1D chloride ingress $\mathrm{G} 2$ is slag concrete exposed to 2D chloride ingress $\mathrm{Y} 1$ is beam with reinforcement bar placed in middle $\mathrm{Y} 2$ is beam with reinforcement placed at an orthogonal corner $\mathrm{N}$ is specimen label (A,B, or $\mathrm{C})$

Figure 1: Cross section of steel reinforced concrete beam exposed to (a) 1D and (b) 2D chloride ingress.

The cracked beams were loaded in rigs (see Figure 2) to prevent the incipient cracks from sealing.

Both the cracked and uncracked beams ( 6 beams each) were subjected to a repeated cycle of 2 week ponding in a $5 \%$ chloride solution followed by 2 week exposure to air-drying in ambient laboratory conditions [27].

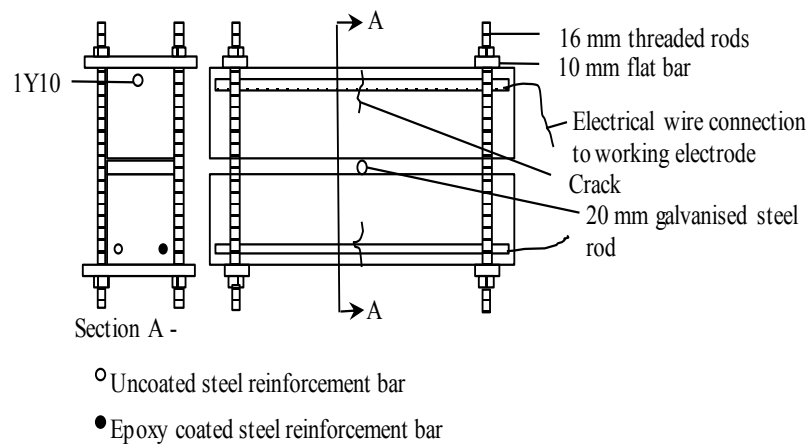

Figure 2: Loading of cracked specimens on rigs

While the concrete beams with single plain reinforcement bars placed (longitudinally) at the middle of the beam were subjected to $1 \mathrm{D}$ chloride ingress, the beams with a coated and plain steel reinforcement bar 
(both placed at opposite orthogonal corners) were exposed to 2D chloride ingress (Figure 1).

\subsection{Corrosion assessment methods}

Steel corrosion potential measurements were taken using the copper/copper sulfate half-cell electrode potential meter (ASTM C876-09), concrete resistivity was measured using the one electrode-disc method while the corrosion rate data was collated using a Coulostat device. In taking the concrete resistivity measurements, the single electrode-disc method was used. The measurements obtained with the single electrode-disc method can reasonably be assumed to estimate the concrete cover resistivity which is adjudged to provide better corrosion rate estimates compared to bulk or local concrete resistivity measurements which may lead to errors in the corrosion rate estimation. The concrete cover resistivity also provides a measure of its resistance to penetration of chloride ions.

The single electrode-disc concrete resistivity measurement method involves the application of a current charge via a disc and the resulting voltage measured across the circuit. The concrete resistivity is then computed using Equation 1, the cell constant is approximately $0.1 \mathrm{~m}$;

$$
\rho=0.1 \times R(\text { disc }- \text { bar })
$$

where $\rho=$ concrete resistivity, $R=$ ratio between observed voltage and applied current $(V / I)$, disc and reinforcement bar diameters

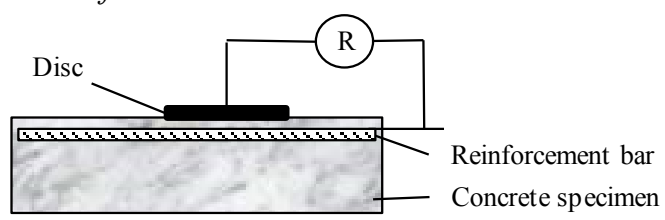

Figure 3: Set up of one electrode-disc method of measuring concrete resistivity [29]

The corrosion measurements were taken about 24 hours after the specimens are removed from the chloride solution (at end of ponding) and 24 hours before they are returned back into the chloride solution (at end of air drying period).

\section{Results and Discussion}

\subsection{Steel corrosion rate measurements}

The plots of steel corrosion rate against time are presented in Figure 4 andFigure 9Figure 5. The results are a 4-point moving average of corrosion rate measurements taken from 3 beam specimens at the end of the wetting and drying cycle.

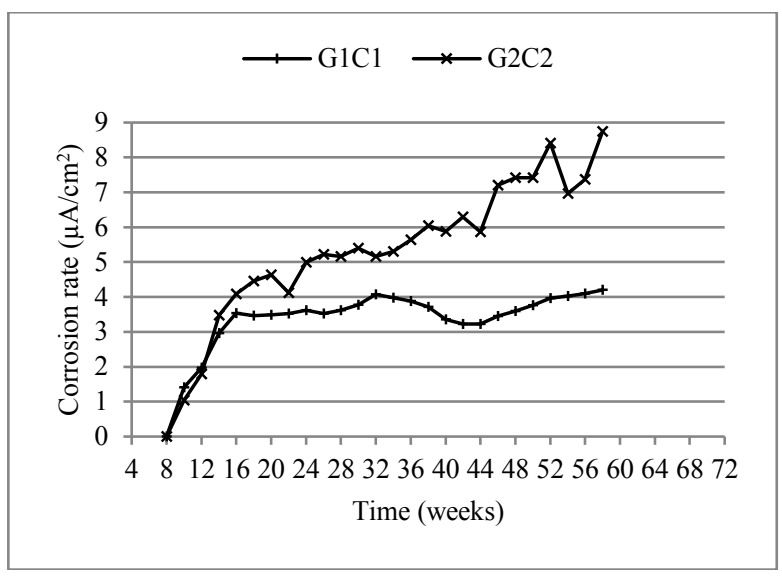

Figure 4: 4-point moving average of corrosion rate vs time (cracked PC/GGBS concrete)

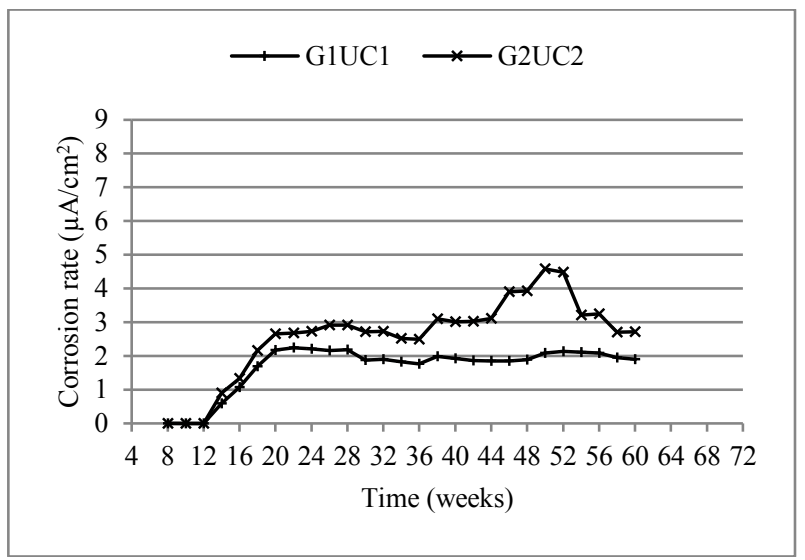

Figure 5: 4-point moving average of corrosion rate vs time (uncracked PC/GGBS concrete)

In Figure 4 andFigure 5, it can be seen that the corrosion rate of the reinforcement bars placed in the concrete specimens exposed to $2 \mathrm{D}$ chloride ingress are higher than that of specimens subjected to 1D chloride ingress by up to $51.96 \%$ in the cracked and $32.85 \%$ in the uncracked concrete specimens. Hence, the corrosion rate of the reinforcement bars at orthogonal corners of the cracked beam specimens proceeds at a rate which is more than twice as fast as that that of steel reinforcement which is placed at the middle of a concrete section. This could be due to dimensional interaction of penetrating of chlorides; oxygen and moisture from adjacent faces of the beam, and since more corrosion causing agents are able to reach the reinforcement rod, the corrosion process proceeds at a faster rate. 


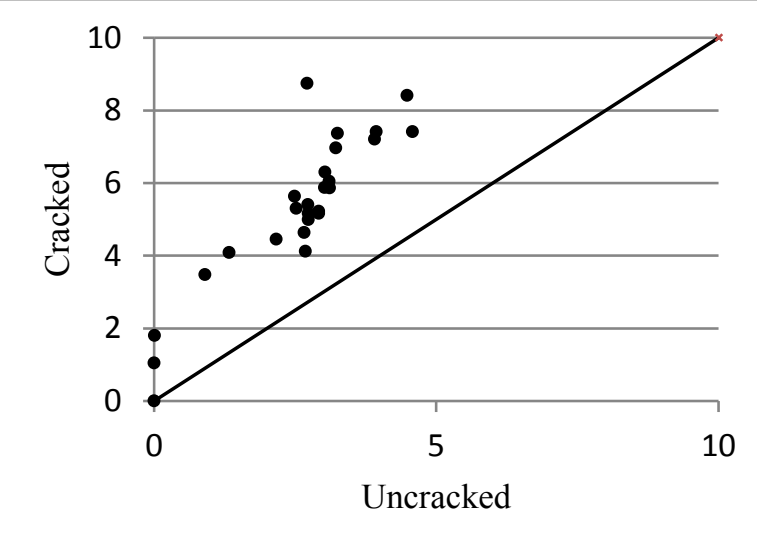

Figure 6: Corrosion rate of cracked vs uncracked RC beam specimens subjected to $2 \mathrm{D}$ chloride ingress

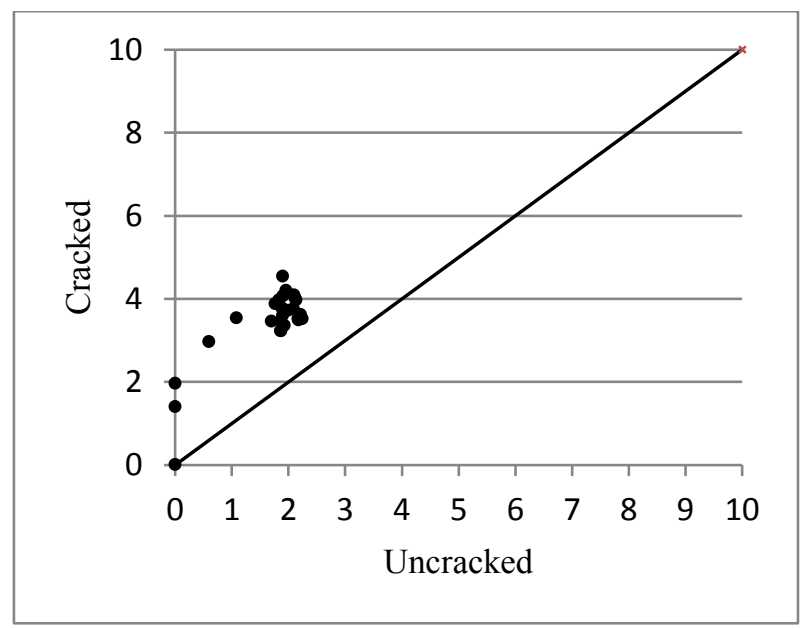

Figure 7: Corrosion rate of cracked vs uncracked RC beam specimens subjected to $1 \mathrm{D}$ chloride ingress

The plots (Figure 6: Corrosion rate of cracked vs uncracked RC beam specimens subjected to $2 \mathrm{D}$ chloride ingressand Figure 7) show that the corrosion rates of the cracked beam specimens are higher than that of the uncracked beam specimens. This signify that the presence of cracks in the concrete have an influence on the corrosion rate measurements, however, the influence of the cracks is more pronounced in the beam specimens exposed to $2 \mathrm{D}$ chloride ingress.

\subsection{Concrete resistivity measurements}

The concrete resistivity plots (Figure 8 and Figure 9) are 4-point moving average of data collated from the fifth month after the commencement of the experiment.

The variation of concrete resistivity with time is shown in the plots (see Figure 8 and Figure 9) above. It can be deduced from the plots that the cracked specimens exposed to $2 \mathrm{D}$ chloride ingress have higher concrete resistivity than those exposed to $1 \mathrm{D}$ chloride ingress. This may be due to the larger exposed concrete surface area which allows greater chloride penetration and easy air-drying of the concrete. The presence of cracks also allow for easy drying out of the concrete which results in higher concrete resistivity measurements than the specimens exposed to 1D chloride ingress.

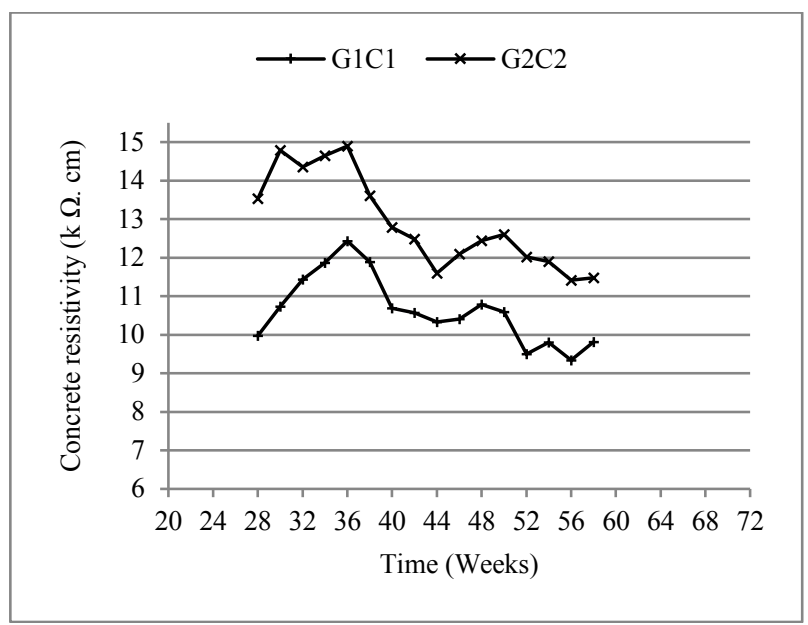

Figure 8: Moving average of concrete resistivity vs time (cracked PC/GGBS concrete)

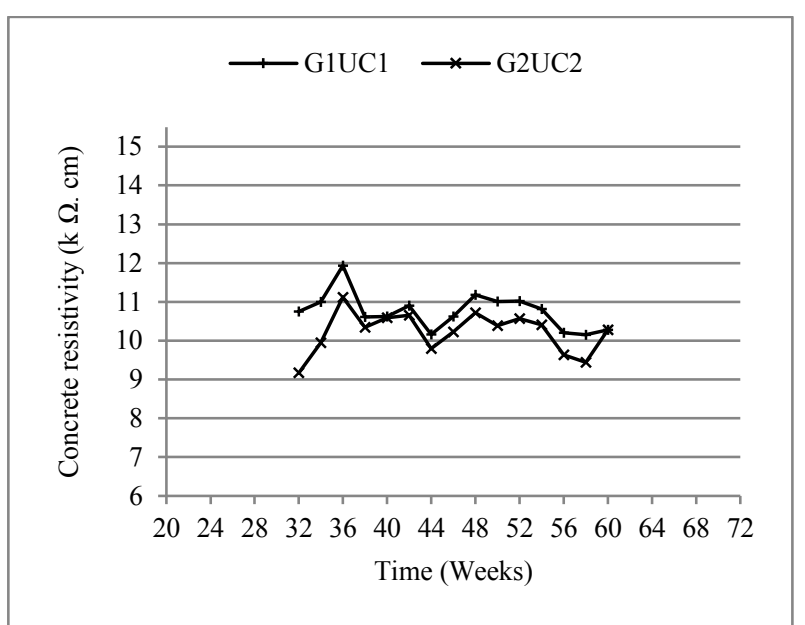

Figure 9: Moving average of concrete resistivity vs time (uncracked GC/GGBS concrete)

The concrete resistivity of the cracked specimens exposed to both $1 \mathrm{D}$ and $2 \mathrm{D}$ chloride penetration have a continually decreasing trend, however the decline in the concrete resistivity of the uncracked specimens is not as apparent as that of the cracked beam specimens. The declining trend in concrete resistivity is due to ingress and increase in chloride concentration in the concrete.

\subsection{Relationship between corrosion rate and concrete resistivity}

The relationship between corrosion rate and concrete resistivity can be seen in the plots below (Figure 10 Figure 13); 


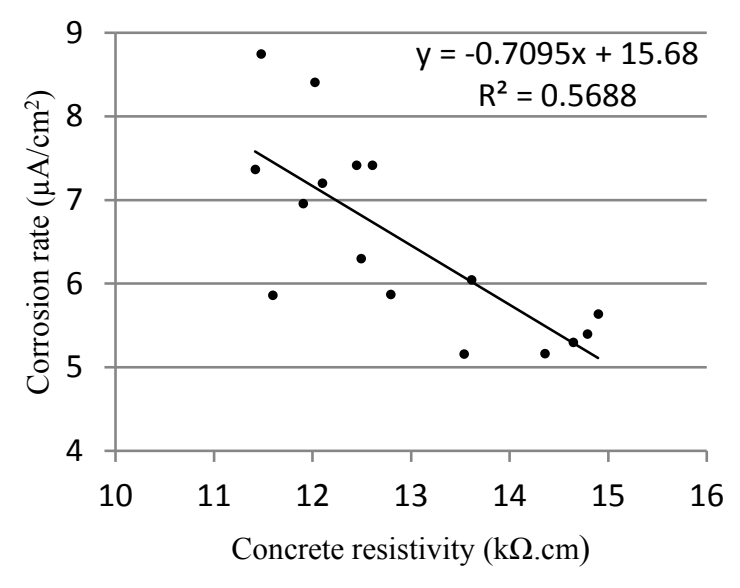

Figure 10: Corrosion rate vs concrete resistivity of cracked concrete exposed to $2 \mathrm{D}$ chloride ingress

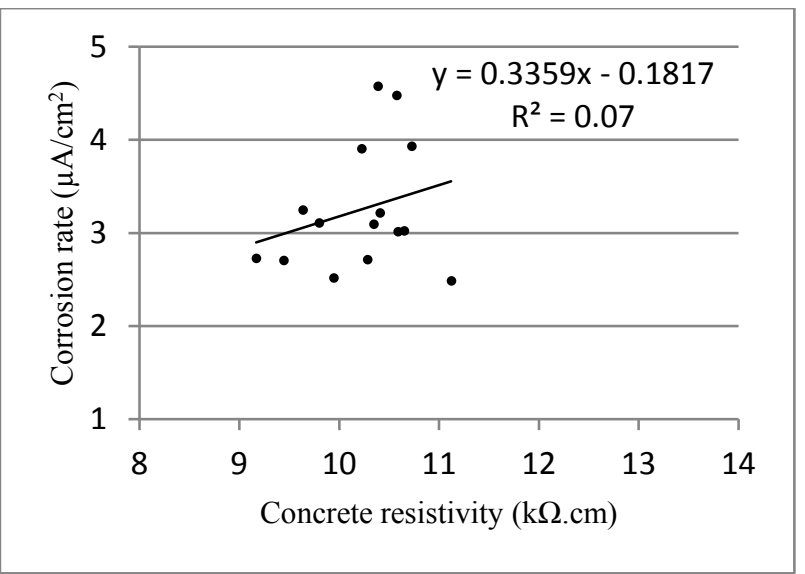

Figure 11: Corrosion rate vs concrete resistivity of uncracked concrete exposed to $2 \mathrm{D}$ chloride ingress

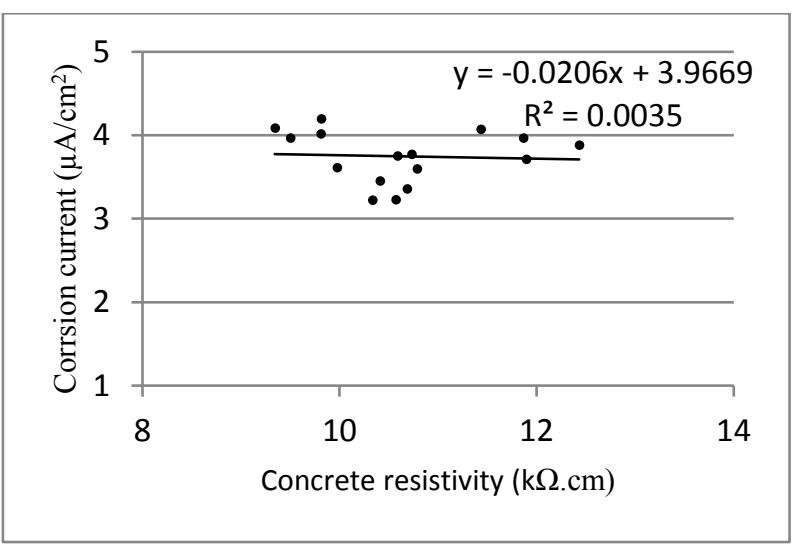

Figure 12: Corrosion rate vs concrete resistivity of cracked concrete exposed to $1 \mathrm{D}$ chloride ingress

A negative slope in the corrosion rate, concrete resistivity plots (Figure 10, Figure 12 and Figure 13) show an inverse relationship between the two parameters. However, the most significant relationship (indicated by a steep slope gradient) is noticed in the cracked specimen exposed to $2 \mathrm{D}$ chloride ingress (Figure 10). A change in the concrete resistivity of both cracked and uncracked specimens exposed $1 \mathrm{D}$ chloride ingress is seen to have a far lesser effect on the corrosion rate.

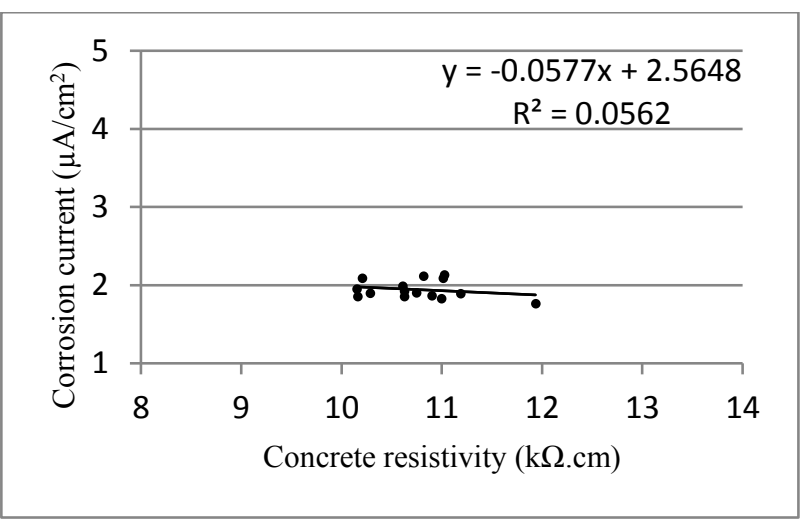

Figure 13: Corrosion rate vs concrete resistivity of uncracked concrete exposed to $1 \mathrm{D}$ chloride ingress

Figure 11 shows that an increase in concrete resistivity in the uncracked concrete subjected to $2 \mathrm{D}$ chloride ingress results in an increase in the corrosion rate. This trend is not consistent with the information in Figure 5 and Figure 9, where an increase in the concrete resistivity results in a reduction in the corrosion rate. Hence the relationship between corrosion rate and concrete resistivity (as presented in Figure 11) of the concrete specimens subjected to $2 \mathrm{D}$ chloride ingress cannot be said to be hold true.

\section{Conclusion}

Preliminary conclusions are that the effect of 2D chloride ingress significantly increased the steel corrosion rate in of the cracked concrete specimens (by $51.96 \%$ ) while the difference in corrosion rate between specimens exposed to $1 \mathrm{D}$ and $2 \mathrm{D}$ chloride ingress is $32.85 \%$. Though the damage due to the corrosion has not been reported in this paper, significant damage at the corner of the concrete element was noticed in the beam specimens exposed to $2 \mathrm{D}$ chloride ingress as compared to those exposed to $1 \mathrm{D}$ chloride ingress.

The results of this study indicate that corrosion commences earlier in the cracked specimens, but the steel corrosion rate in specimens exposed to $2 \mathrm{D}$ chloride ingress increases markedly compared to that of specimens exposed to $1 \mathrm{D}$ chloride ingress.

This paper is a part of an ongoing research, further investigation of the chloride concentration at the depth of the steel reinforcement, and resulting concrete damage due to the corrosion process are still being undertaken. The study will be concluded with the development of a prediction model of the based on corrosion rate and concrete resistivity measurements.

\section{REFERENCES}

[1] M. Torres-Luque, E. Bastidas-Arteaga, F. Schoefs, M. Sánchez-Silva, and J. F. Osma, Constr. Build. Mater., 68, pp. 68-81, (2014)

[2] J. P. Broomfield," Corrosion of Steel in Concrete Understanding, Investigation and Repair", (2nd Edition. London and New York: Taylor \& Francis 
Group, 2007)

[3] L. Peng and M. G. Stewart, Conc. Inst. of Australia, 41, 3, pp. 36-47, (2015)

[4] A. Castel, T. Vidal, R. François, and G. Arliguie, "Mag. of Conc. Res., 55, 2, pp. 151-159, (Apr2003)

[5] A. Castel and D. Jenkins, Conc. Inst. of Australia, 41, 3, pp. 36-64, (2015)

[6] K. G. Papakonstantinou and M. Shinozuka, Eng. Struct., 57, pp. 306-326, (2013)

[7] S. Caré and A. Raharinaivo, Cem. Concr. Res., 37, 12, pp. 1598-1612, (2007)

[8] C. Andrade and C. Alonso, Mater. Struct., 37, 9, pp. 623-643, (2004)

[9] M. Otieno, H. Beushausen, and M. Alexander, Mater. Struct., 49, 6, pp. 1-18, (2015)

[10] M. B. Otieno, "The Development of Empirical Chloride-induced Corrosion Rate Prediction Models for Cracked and Uncracked Steel Reinforced Concrete Structures in the Marine Tidal Zone," (University of Cape Town, 2014)

11] N. T. Tran and Q. Huang, "Influence of Cracks on Chloride-Induced Corrosion in Reinforced Concrete Structures," (Chalmers University of Technology, Gothenburg, Sweden, 2006)

[12] K. Hornbostel, C. K. Larsen, and M. R. Geiker, Cem. Concr. Compos., 39, pp. 60-72, (2013)

[13] H. Zhang, W. Zhang, X. Gu, X. Jin, and N. Jin, Struct. Infrastruct. Eng., 12, 11, pp. 1428-1438, (2016)

[14] B. Kang and H. Shim, Int. J. Railw., 4, 4, pp. 8692, (2011)

[15] L. Jin, R. Zhang, X. Du, and Y. Li, Constr. Build. Mater., 95, pp. 171-185, (2015)

[16] D. V. Val and P. A. Trapper, 3rd International Conference on Bridge Maintenance, Safety and Management - Bridge Maintenance, Safety, Management, Life-Cycle Performance and Cost, pp. 527-528 (2006)
[17] D. V. Val and P. A. Trapper, Reliab. Eng. Syst. Saf., 93, 3, pp. 364-372, (2008)

[18] Y. Zhang, W. Sun, Z. Liu, and S. Chen, J. Zhejiang Univ. - Sci. A, Applied Phys. Eng., 12, 9, pp. 692701, (2011)

[19] Y. Zhang, W. Sun, S. Chen, and F. Guo, J. Wuhan Univ. Technol. Sci. Ed., 26, 5, pp. 978-982, (2011)

[20] J. Gulikers, Mater. Corros., 56, 6, pp. 393-403, (2005)

[21] M. Pour-Ghaz, O. B. Isgor, and P. Ghods, Corros. Sci., 51, 2, pp. 415-425, (2009)

[22] M. Pour-Ghaz, O. Burkan Isgor, and P. Ghods, Corros. Sci., 51, 2, pp. 426-433, (2009)

[23] A. N. Scott and M. G. Alexander, Mag. Concr. Res., 59, 7, pp. 495-505, (2007)

[24] M. Otieno, "Corrosion Propagation in Cracked and Un-cracked Concrete," (Univeristy of Cape Town, 2008)

[25] Y. Liu and R. E. Weyers, ACI Mater. J., 95, 6, pp. 675-680, (1998)

[26] ASTM G1-90, "Standard Practice for Preparing, Cleaning, and Evaluation Corrosion Test Specimens," (ASTM, p. 8, 2003)

[27] G. Golden, "The Effect of Cyclic Wetting and Drying on the Corrosion Rate of Steel in Reinforced Concrete," (University of Cape Town, South Africa, 2015)

[28] ASTM C876-09, "Standard Test Method for Corrosion Potentials of Uncoated Reinforcing Steel in Concrete, "(ASTM 2009)

[29] P. Azarsa and R. Gupta, Adv. Mater. Sci. Eng., 2017, (2017) 